\title{
Patient Perspectives and Expectations in Inflammatory Bowel Disease: A Systematic Review
}

\author{
Alex Al Khoury ${ }^{1} \cdot$ Bhairavi Balram $^{3} \cdot$ Talat Bessissow $^{2} \cdot$ Waqqas Afif $^{2} \cdot$ Lorant Gonczi $^{4} \cdot$ Maria Abreu $^{1}$. \\ Peter L. Lakatos ${ }^{2,4,5}$ (i)
}

Received: 26 February 2021 / Accepted: 21 April 2021 / Published online: 21 May 2021

(c) The Author(s), under exclusive licence to Springer Science+Business Media, LLC, part of Springer Nature 2021, corrected publication 2021

\begin{abstract}
Background In this systematic review, our objective was to assess inflammatory bowel disease (IBD) patient preferences and perspectives relating to their disease diagnosis, treatment, knowledge needs and telemedicine.

Methods This study was conducted in accordance with the Preferred Reporting Items for Systematic Reviews and Meta-Analyses guidelines. Four databases and conference proceedings were searched between January 1, 1980, and May 1, 2020. The methodological quality of the included studies was assessed using the Standards for reporting qualitative research checklist. Results Our search identified 240 citations and 52 studies met the inclusion criteria. The major expectations of the patients are symptomatic and pain control, quality of life and normal endoscopy. Patients' main concerns are access to information and healthcare, and shared decision making. At the time of diagnosis, patients expressed a greater need for knowledge about their IBD, preferentially by their treating gastroenterologist. The main treatment expectations in active disease are efficacy, safety and convenience. Patients are willing to accept relatively high risks of complications from medical therapy to avoid a permanent ostomy and to achieve durable remission. Patients are more interested in disease monitoring, research and development during the time of remission. Telemedicine and self-management with supervised e-health tools are feasible and acceptable amongst patients with IBD.

Conclusion This systematic review demonstrates that patients with IBD expect more information about their disease process, shared decision making and symptom control. Further research is needed to help align patient and physician expectations in order to improve the quality of care provided to patients with IBD.
\end{abstract}

Keywords Patient preferences $\cdot$ Patient perspectives $\cdot$ Access $\cdot$ Shared decision making $\cdot$ Telemedicine $\cdot$ Systematic review

Peter L. Lakatos

Peter.Lakatos@muhc.mcgill.ca; peter.lakatos@mcgill.ca; kislakpet99@gmail.com

\author{
Alex Al Khoury \\ alexkhoury88@gmail.com \\ Bhairavi Balram \\ balram@ualberta.ca \\ Talat Bessissow \\ talat.bessissow@gmail.com \\ Waqqas Afif \\ waqqas.afif@mcgill.ca \\ Lorant Gonczi \\ lorantgonczi@gmail.com \\ Maria Abreu \\ mabreu1@med.miami.edu
}

1 University of Miami Miller School of Medicine, Gastroenterology, Miami, USA

2 Division of Gastroenterology, Department of Medicine, McGill University, Montreal, Canada

3 Division of Gastroenterology, University of Alberta, 130 University Campus NW, Edmonton, AB, Canada

4 First Department of Medicine, Semmelweis University, Budapest, Hungary

5 McGill University Health CentreMcGill University Health Centre, Montreal General Hospital, 1650 Ave. Cedar, D16.173.1, Montreal, QC H3G 1A4, Canada 


\section{Introduction}

Inflammatory bowel diseases (IBD), consisting of ulcerative colitis (UC) and Crohn's disease (CD), are chronic immunemediated disorders of the gastrointestinal tract that can negatively impact patients' physical health and quality of life. Those with extraintestinal manifestations (EIM) irrespective of disease activity showed worse quality of life than those without EIM both physically and psychologically [1]. The incidence and prevalence of IBD is increasing worldwide, placing a significant burden on both patients and the health care system [2].

The approach to management of IBD has evolved in the past years with tight and objective disease monitoring to achieve endoscopic remission [3]. This predicts long-term steroid free remission and lower surgical and hospitalization rates [4-7]. Most recently, STRIDE II confirmed STRIDE I long-term targets of clinical remission and endoscopic healing and further added the absence of disability and normal quality of life as long-term targets [8].

Despite the advancement in pharmacological management of IBD, patients may experience loss of response due to reasons such as antibody formation and development of drug-related complications such as serious infections and malignancies requiring discontinuation [9-13]. Therefore, the management of IBD is complex requiring tight control of disease activity, close monitoring to minimize drug-related side effects, expertise in the field and an interdisciplinary holistic approach to patient care [14].

Herein, the chronic relapsing nature of IBD requires a long-term patient-oriented interaction and effective communication between the patient and the physician. This is important to optimize patient involvement in their care and shared decision-making [15]. Patient satisfaction is thought to be an integral part of high quality of care (QoC) yet complex assessment of perceived QoC from the patients' perspective is scarce [16]. The European Crohn's and Colitis Organization (ECCO) developed criteria to summarize optimal standards of care in IBD [14]. In order to provide a high QoC delivery, it is essential for medical providers to evaluate patients' satisfaction and expectations when providing care.

Patient expectations differ at diagnosis, during a flare, remission as well as across different countries [17]. Studies have shown that at diagnosis, patient education and support are important. During treatment, efficacy, rapid improvement of symptoms, medication safety profile, and convenience with simplicity are key. During follow-up, patients considered cancer risk and management of complications as important measures [18-21]. It is imperative to be aware of these different aspects of patient expectations during IBD management in order to provide optimal patient care.

To our knowledge, there has not been any systematic review published on patient perspectives and expectations in IBD during shared decision making. A narrative review by Bewtra et al. [22] explored patient preferences in IBD therapy. In this review, we aimed to assess IBD patient preferences and perspectives during various stages of their disease, specifically, relating to their disease at diagnosis, both during active disease and in remission, longstanding disease treatment, knowledge needs, and telemedicine.

\section{Methods}

\section{Data Sources and Search Strategy}

This study was conducted in accordance with the Preferred Reporting Items for Systematic Reviews and Meta-Analyses guidelines (PRISMA). [23] We searched the Cumulative Index to Nursing and Allied Health Literature, Medline, Embase, BIOSIS, and Web of Science between January 1, 1980, and May 1, 2020. Conference proceedings were searched (World Congress of Gastroenterology, American College of Gastroenterology, Canadian Digestive Disease Week, Digestive disease week and United European Gastroenterology Week) between January 1, 1980, and May 1, 2020. We searched study references and review articles and contacted authors for additional data. Abstracts and brief reports were not included. The search strategies for patient perspectives and expectations in IBD are outlined in Table 1. Studies were independently selected by two reviewers (BB and $\mathrm{AK}$ ); disagreements were resolved by a third reviewer (PLL).

\section{Study Selection}

We included studies that investigated adult IBD populations (diagnosis of UC or CD per conventional definitions); specifically, patient perspectives, expectations or preferences at the time of IBD diagnosis, during remission, related to

Table 1 Search string

Medline search strategy

\#1 (Inflammatory Bowel Disease [MeSH] OR Crohn's disease [MeSH] OR Ulcerative Colitis [MeSH] OR 'Crohn's disease' [ti] OR

'Ulcerative Colitis' [ti]), AND \#2 ('patient' [ti]), AND \#3 ('preference' [ti] or 'satisfaction' [ti] or 'education' [ti] or 'needs' [ti] or 'infor-

mation' [ti] or 'expectations' [ti] or 'telemedicine' [ti] or 'decision making' [ti] or 'quality indicator' [ti]) 
treatment and telemedicine. We excluded studies if: (1) if they were not related to our outcome of interest, (2) were not written in English, and (3) they were only available as an abstract or brief report. We accepted cohort, case-control and cross-sectional studies.

\section{Data Extraction}

We used a standardized data extraction form. Variables extracted included, (1) study characteristics-primary author, time period of study, location, study design, measurement tools, (2) patient characteristics—age, gender, IBD subtype (UC or CD), patient population (3) patient perspectives/preferences/expectations at the time of diagnosis, during remission, regarding treatment and telemedicine and (4) covariates and between group variables evaluated.

The methodological quality of the included studies was assessed using the Standards for reporting qualitative research (SRQR) checklist [24]. Studies were scored across four categories: Introduction (four questions), Methods (eleven questions), Results (two questions) and Discussion (four questions) with one point per question in each category (Supplemental Table 1). Study quality was defined as low, moderate and high, based on scores of 0-7, 8-14 and 15-21, respectively. Two reviewers (BB and $\mathrm{AK}$ ) extracted data and assessed quality independently; disagreements were resolved by a third reviewer (PLL).

\section{Results}

\section{Search Results}

Our search identified 236 citations and fifty-two studies met the inclusion criteria (Fig. 1). The majority of the studies were cross-sectional (43/52). There were three cohort studies, one case-control study and three randomized controlled trials [25-31]. There were two studies that did not state their study design [20,32]. Twenty-six studies were published in North America, twenty in Europe, four in Asia and two in Oceania. The major expectations of the patients are symptomatic control, pain control, quality of life, and normal endoscopy. Patients' main concerns are information, access, and shared decision making.

\section{Patient Characteristics}

Thirty-five studies included both CD and UC patients. Eleven studies evaluated patients with UC and six studies included only patients with $\mathrm{CD}$.
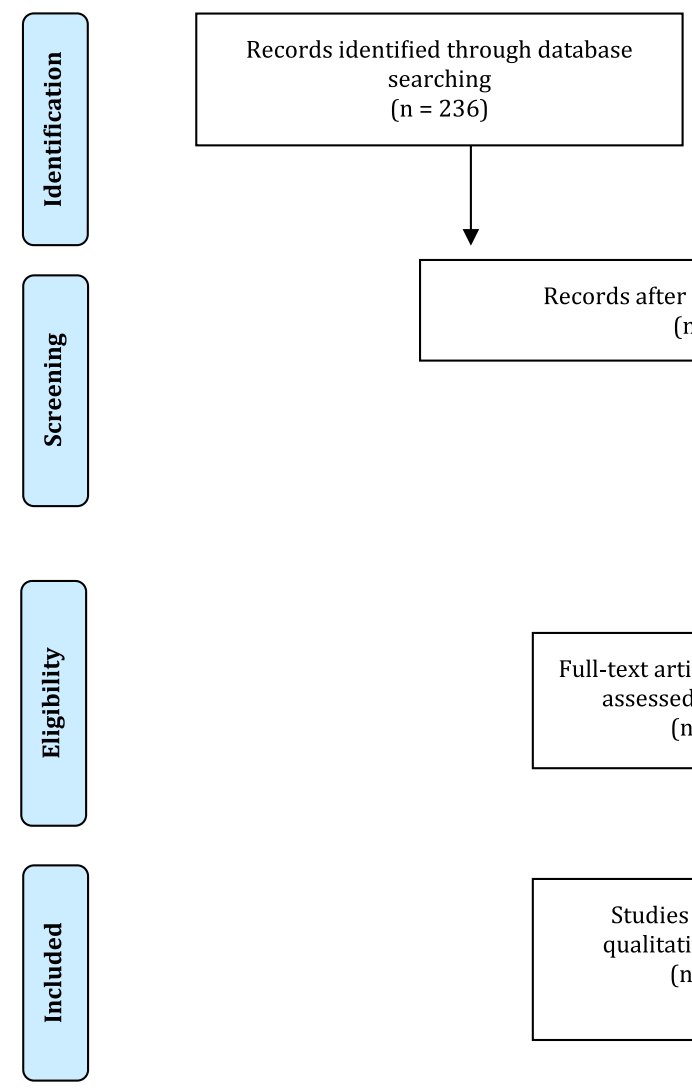

Additional records identified through other sources $(n=4)$
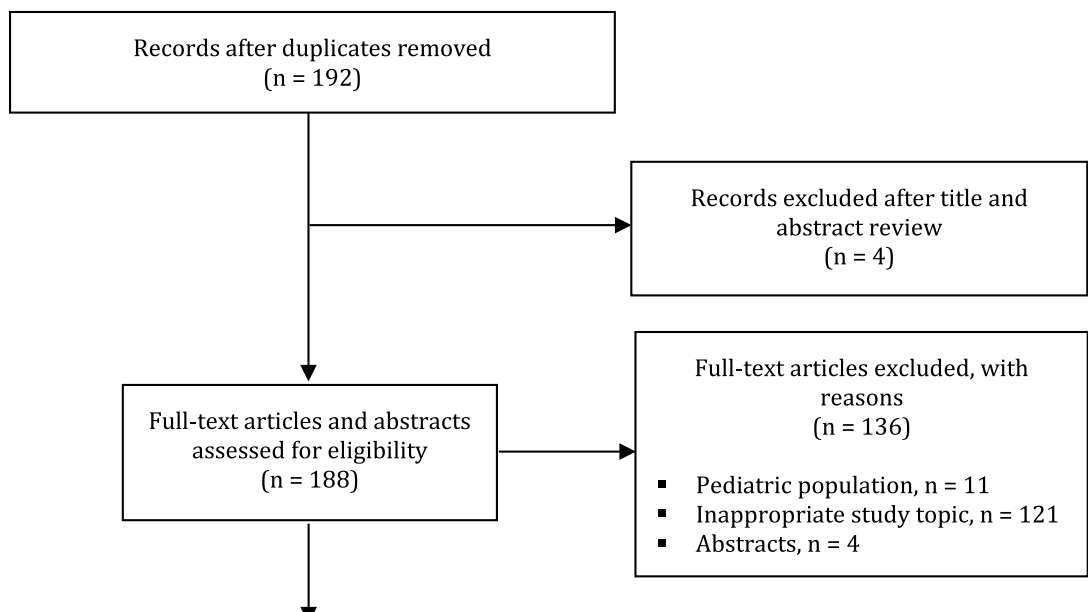

Studies included in qualitative synthesis $(\mathrm{n}=52)$

Fig. 1 Flowchart of study selection 


\section{Patient Perspectives and Expectations at the Time of Diagnosis}

There were four studies that evaluated patient perspectives and expectations at the time of diagnosis [33-36]. The conclusion from three of these studies was that patients expressed a greater need for knowledge at the time of diagnosis [34-36]. Table 2 outlines the study characteristics and outcomes. Studies compared variables such as age, sex and severity of disease and information needs at diagnosis varied amongst different patient populations. Patient with more severe, active disease had higher information needs, especially around domains of work-disability, stress-coping and therapy-complications [34]. Patients with a higher level of education than community college had increased desire to participate in self-care [35].

\section{Patient Perspectives and Expectations Regarding Treatment}

There were 18 studies that evaluated patient perspectives and expectations regarding treatment $[18,19,30,32,33$, 37-49]. The majority of these studies were conducted in North America (13/18) [18, 19, 32, 37-40, 42-45, 47, 49]. According to the patients' in multiple studies the most important treatment expectations were related to efficacy, safety and convenience of treatment. [47] There were some differences between CD and UC patients, as UC patients are willing to accept relatively high risks of fatal complications from medical therapy to avoid a permanent ostomy and to achieve durable remission, thus being more efficacy driven [40]. Similarly, CD patients would accept a rare risk of infection or cancer for an increased chance of remission, yet $\mathrm{CD}$ patients rated the side effect profile of the medications as very important in their decision making [19, 37, 43, 44]. In contrast, in exchange for improvements from moderate symptoms to remission for the middle-aged patient profile, gastroenterologists were significantly less tolerant than patients of treatment risks of serious infection and lymphoma [44]. An additional factor was the route of administration (intravenous vs. subcutaneous vs. oral) and need for repeated daily dosing $[38,47]$. Table 3 outlines the study characteristics and outcomes regarding treatment perspectives and expectations.

\section{Patient Perspectives and Expectations During Remission}

There were nine studies investigating IBD patient perspectives while in remission (Table 4) [15, 25, 29, 38, 50-54]. Overall, patients are more interested in drug monitoring, access to healthcare as well as research and development during remission [52]. Patients prefer non-invasive stool testing such as fecal calprotectin for monitoring disease activity to colonoscopy as long as the stool test is accurate. [50]. The paper by Morishige et al. [15] demonstrated that patients valued shared decision making concerning their treatment. Patients expected good coordination between specialists and family physicians [29]. Patients considered symptom control more important than the time to symptom control [38]. They also preferred improvement in the quality of life as an important treatment objective over a completely normal colonoscopy [25].

\section{IBD Patient Information Needs}

There were fourteen studies that evaluated information needs amongst patients with IBD (Table 5). Seven studies concluded that patients with IBD were dissatisfied with the information that they received, specifically related to treatment side effect profile, cancer risk and research trials [35, $36,55-58]$. Four studies demonstrated that patients prefer gastroenterologists to be their primary source of information $[35,55,56,59]$. Information needs varied across variables such as age and disease severity. Patient with more severe, active disease had higher information needs, especially around domains of work-disability, stress-coping and therapy-complications.

\section{IBD and Telemedicine}

There were eight studies investigating telemedicine in IBD (Table 6). Overall, telemedicine (web or text message based) is acceptable and feasible amongst patients with IBD [26-28, 60, 61]. Telemedicine reduced the number of outpatient visits. In the era of COVID-19, telemedicine has become part of patient expectations. However, compared to conventional management, two studies demonstrated no reduction in the frequency of hospitalizations, whereas two studies showed that there was a reduction in hospitalizations [26-28, 31].

\section{Methodological Quality}

Overall, the studies received a high score for methodological quality. Using the SRQR checklist, the average score amongst studies was 17.7. The majority of studies lost points for not including funding sources, conflicts of interest and ethical issues pertaining to human subjects.

\section{Discussion}

The results of this systematic review demonstrate that patients with IBD expect overall access, symptom control and more information about their disease and treatment 
Table 2 Patient perspectives related to IBD diagnosis

\begin{tabular}{|c|c|c|c|c|c|c|c|c|}
\hline Author & $\begin{array}{l}\text { Study } \\
\text { Publication } \\
\text { Date }\end{array}$ & Location & Patient population & IBD & Study size & Female (\%) & Variables & Outcomes \\
\hline Bernstein [35] & 2011 & Canada & NA & $\mathrm{UC}+\mathrm{CD}$ & 74 & $53 \%$ & $\begin{array}{l}\text { Age, sex, diag- } \\
\text { nosis (UC vs. } \\
\text { CD), level of } \\
\text { education }\end{array}$ & $\begin{array}{l}\text { 24\% of patients reported } \\
\text { feeling dissatisfied } \\
\text { with the information at } \\
\text { the time of diagnosis. } \\
\text { Sixty-eight percent } \\
\text { preferred information } \\
\text { from a medical special- } \\
\text { ist. Age and diagnosis } \\
\text { (CD vs. UC) were not } \\
\text { significantly related to } \\
\text { desire for information. } \\
\text { Desire for participation } \\
\text { in self-care was higher } \\
\text { among participants with } \\
\text { a higher level of educa- } \\
\text { tion than community } \\
\text { college. Sex, age and } \\
\text { diagnosis were not } \\
\text { significantly associated } \\
\text { with desire for self-care }\end{array}$ \\
\hline Casellas [33] & 2014 & Spain & NA & UC & 8 & $50 \%$ & Disease severity & $\begin{array}{l}\text { Patients' main concerns } \\
\text { were the delay in diag- } \\
\text { nosis due to the lack of } \\
\text { clinical suspicion by } \\
\text { their general practi- } \\
\text { tioner and the delay in } \\
\text { obtaining the appropri- } \\
\text { ate diagnostic tests. } \\
\text { Patients with moderate } \\
\text { versus mild diagnosis } \\
\text { are more aware of the } \\
\text { need for information } \\
\text { due to the impact of } \\
\text { their UC }\end{array}$ \\
\hline Daher [34] & 2019 & Israel & Multi-ethnic & $\mathrm{UC}+\mathrm{CD}$ & 571 & $46 \%$ & $\begin{array}{l}\text { Age, sex, diag- } \\
\text { nosis (UC vs. } \\
\text { CD), disease } \\
\text { severity }\end{array}$ & $\begin{array}{l}\text { Patients expect more } \\
\text { information at the time } \\
\text { of diagnosis. Patient } \\
\text { with more severe, active } \\
\text { disease had higher } \\
\text { information needs, } \\
\text { especially around } \\
\text { domains of work-disa- } \\
\text { bility, stress-coping and } \\
\text { therapy-complications }\end{array}$ \\
\hline Lesnovska [36] & 2014 & Sweden & Multi-ethnic & $\mathrm{UC}+\mathrm{CD}$ & 30 & $53 \%$ & None & $\begin{array}{l}\text { There was a greater need } \\
\text { for knowledge at the } \\
\text { time of diagnosis and } \\
\text { during relapse. Patients } \\
\text { would have preferred a } \\
\text { long conversation with } \\
\text { their GI specialist at the } \\
\text { time of diagnosis }\end{array}$ \\
\hline
\end{tabular}

process preferentially by the specialist and to partner with us by shared decision-making. To our knowledge, this is the first systematic review to assess patient perspectives and expectations in IBD during shared decision making. 


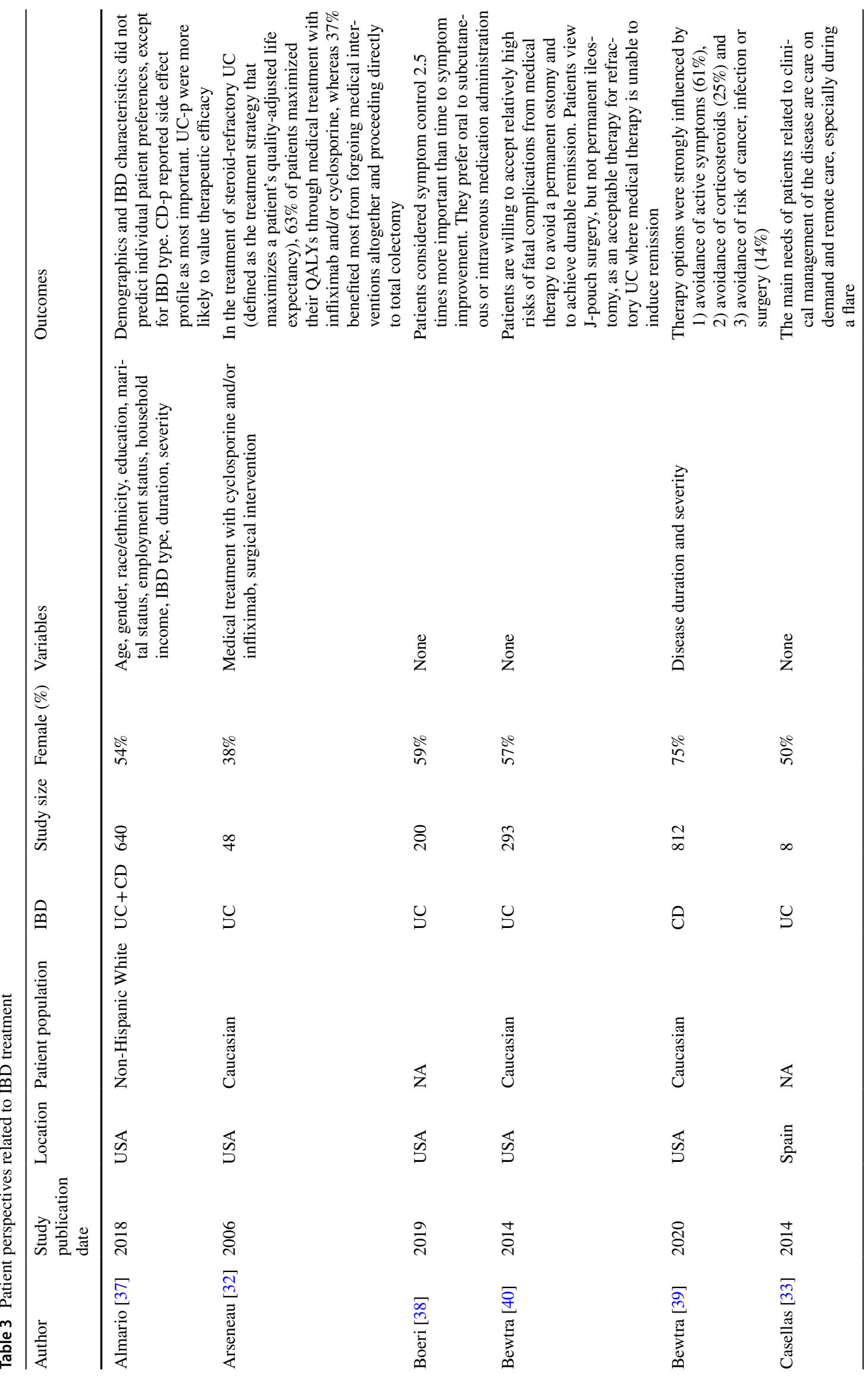




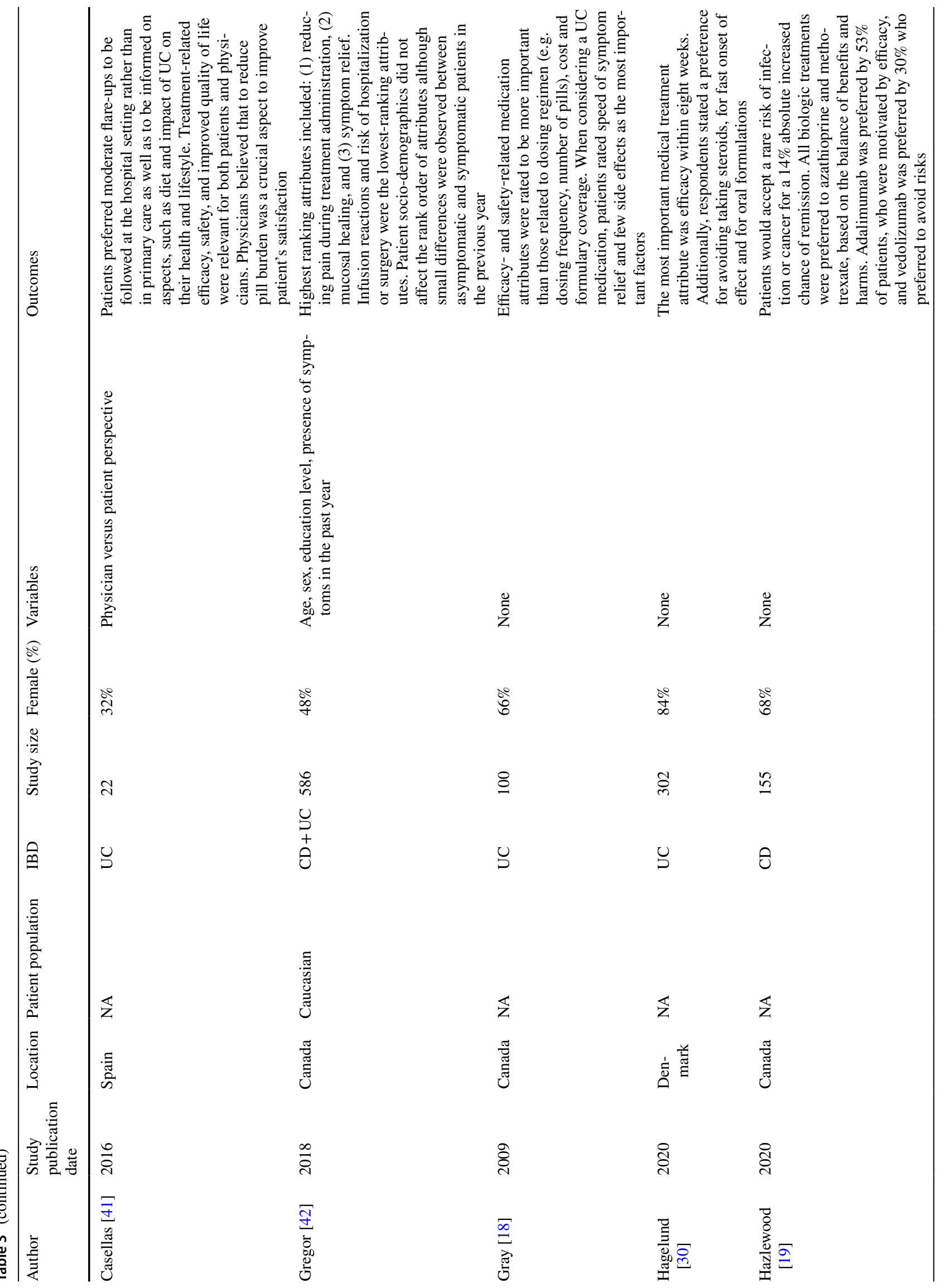




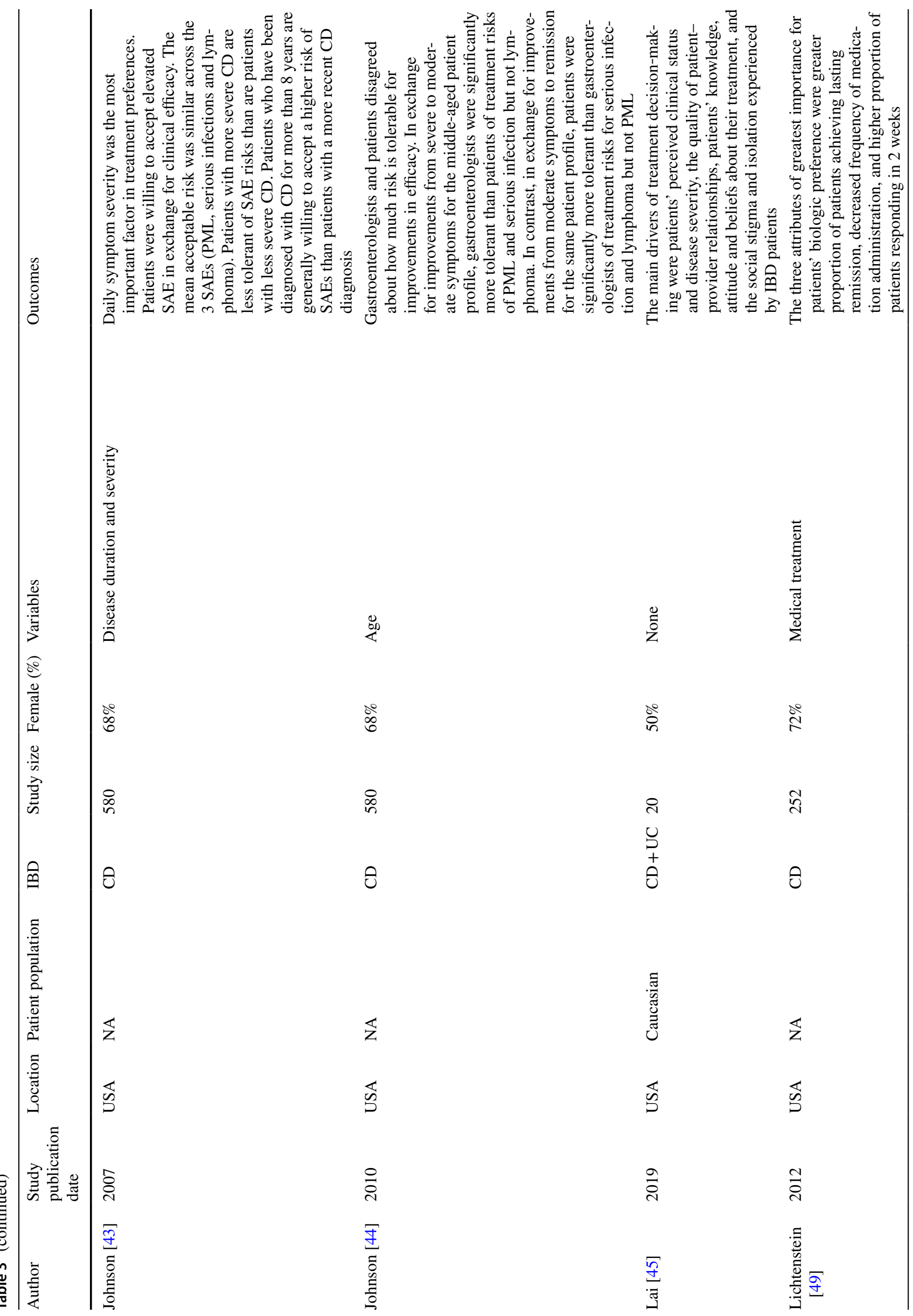




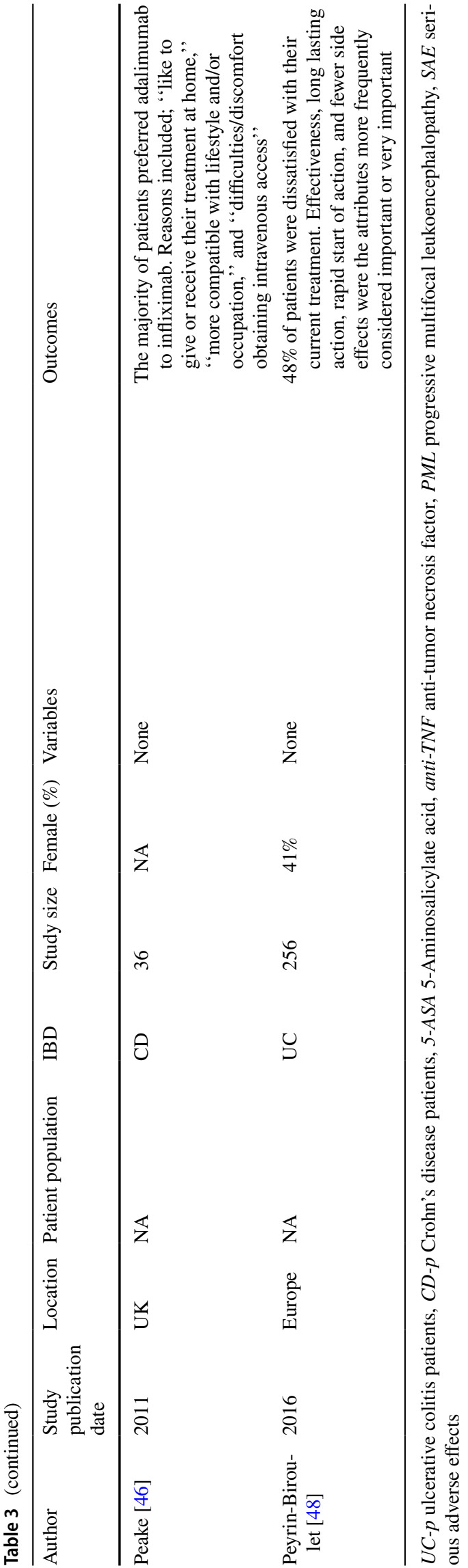

At the time of diagnosis, patients expected a greater need for knowledge of their condition. The preferred source of information is the treating gastroenterologist [56]. A study by Lesnovska et al. showed that there was a greater need for knowledge at the time of diagnosis and during relapse. Patients would have preferred a long conversation with their gastroenterologist at the time of their diagnosis in order to better understand their disease [36]. Pittet et al. [52] showed that nearly half of patients sought for information, regardless of the disease stage and a quarter of them of them were dissatisfied with information received at the time of first symptoms. Therefore, it is important for patients to be actively involved in the decision-making process from the start $[15$, 62].

In active disease patients are mainly concerned about their therapy, efficacy, safety, convenience and access [37, 47, 63]. In terms of patient perspectives and expectations during treatment, patients viewed efficacy of therapy to be most important. During flares, $43 \%$ were concerned about drugs and therapies in a large study by Pittet et al. [52]. A study by Hazlewood et al. [19] demonstrated that patients would accept a rare risk of infection or cancer for a $14 \%$ absolute increase chance of remission Patients were willing to accept elevated serious adverse effects (serious infections, lymphoma) in exchange for clinical efficacy [43]. Convenience (doctor visits, fewer pills) was the third most important aspect of disease management after efficacy and safety. An equally important point is access. In a recent study by our group on assessing patients' reflection on the quality of care this was highlighted as one of the problem areas [37, $47,63]$. Of note, the availability of rapid access option by email, phone to contact the IBD center with a rapid response has also shown to significantly decrease the burden for the patients with lesser utilization of the emergency units and decreasing costs [37, 47, 63, 64].

Furthermore, Casellas et al. showed that the most important treatment objective from the patients' perspective was improving quality of life (40\% of patients) followed by completely resolving symptoms (33\% of patients). Only $12 \%$ of patients considered having a completely normal colonoscopy as a preferred objective [25]. Gregor et al. demonstrated that reducing pain during administration, mucosal healing, and symptom relief were the highest-ranking attributes for out of pocket willing-ness to pay. Conversely, infusion reactions and risk of hospitalization or surgery were the lowestranking attributes [42]. Patients preferred oral to subcutaneous or intravenous administration (relative importance, 0.47 vs. 0.11 and 0.18 , respectively) [38]. When comparing anti TNFs, the majority of patients preferred subcutaneous route to intravenous with ease of use and time required for therapy playing an important role for selection [65]. Interestingly, a study by Almario et al. showed that there was no difference between biologic therapy choice when comparing 


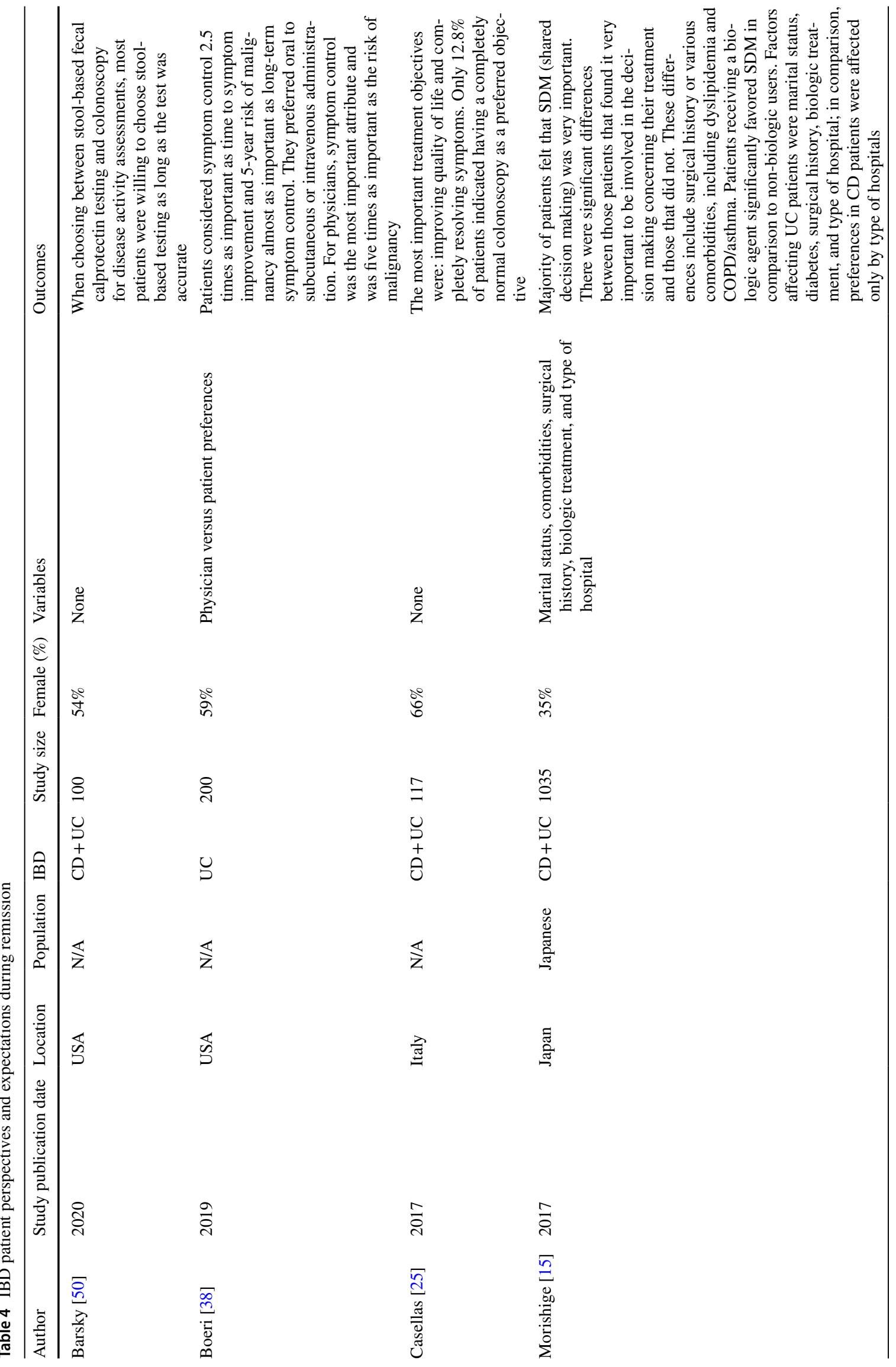




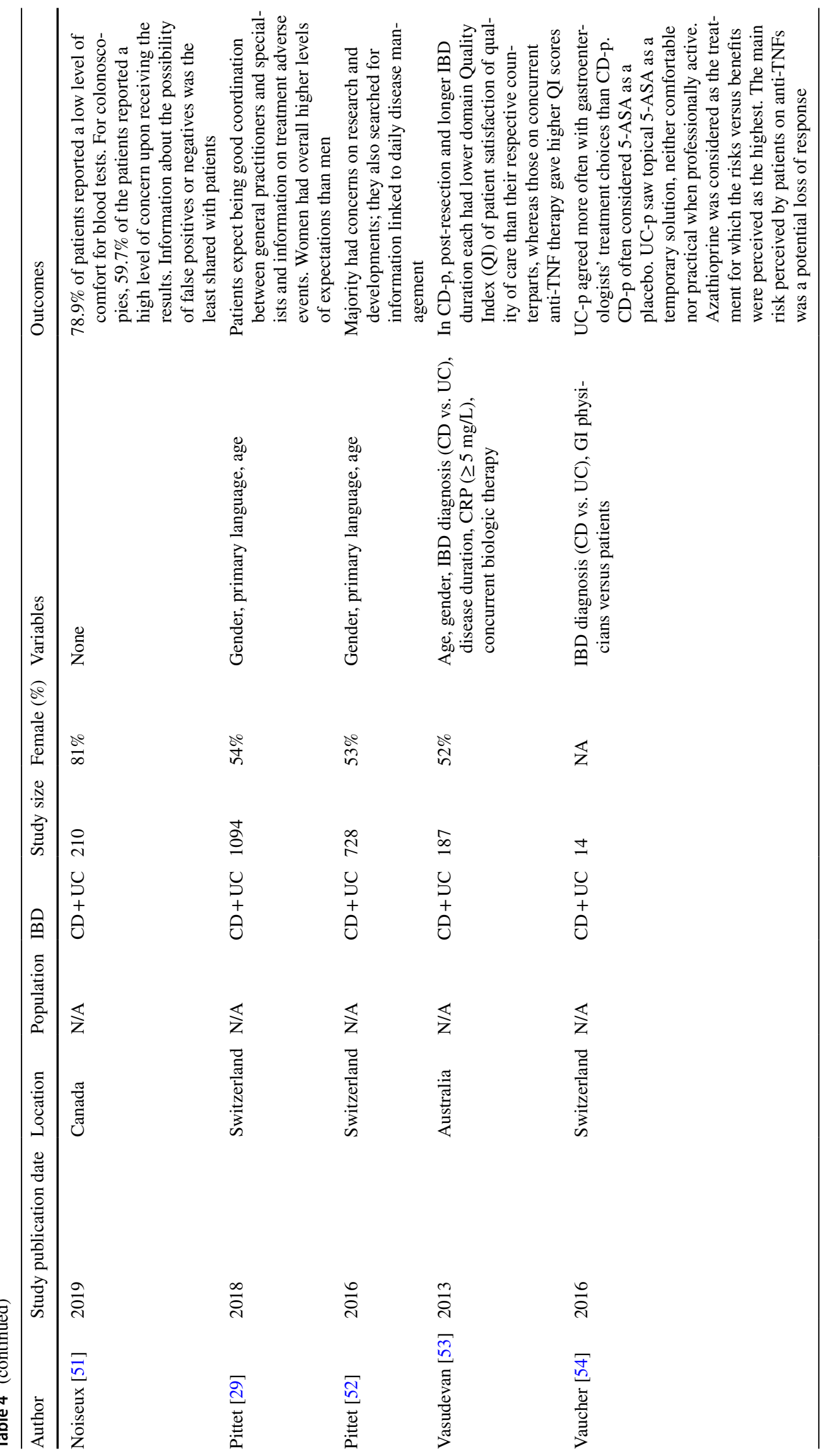




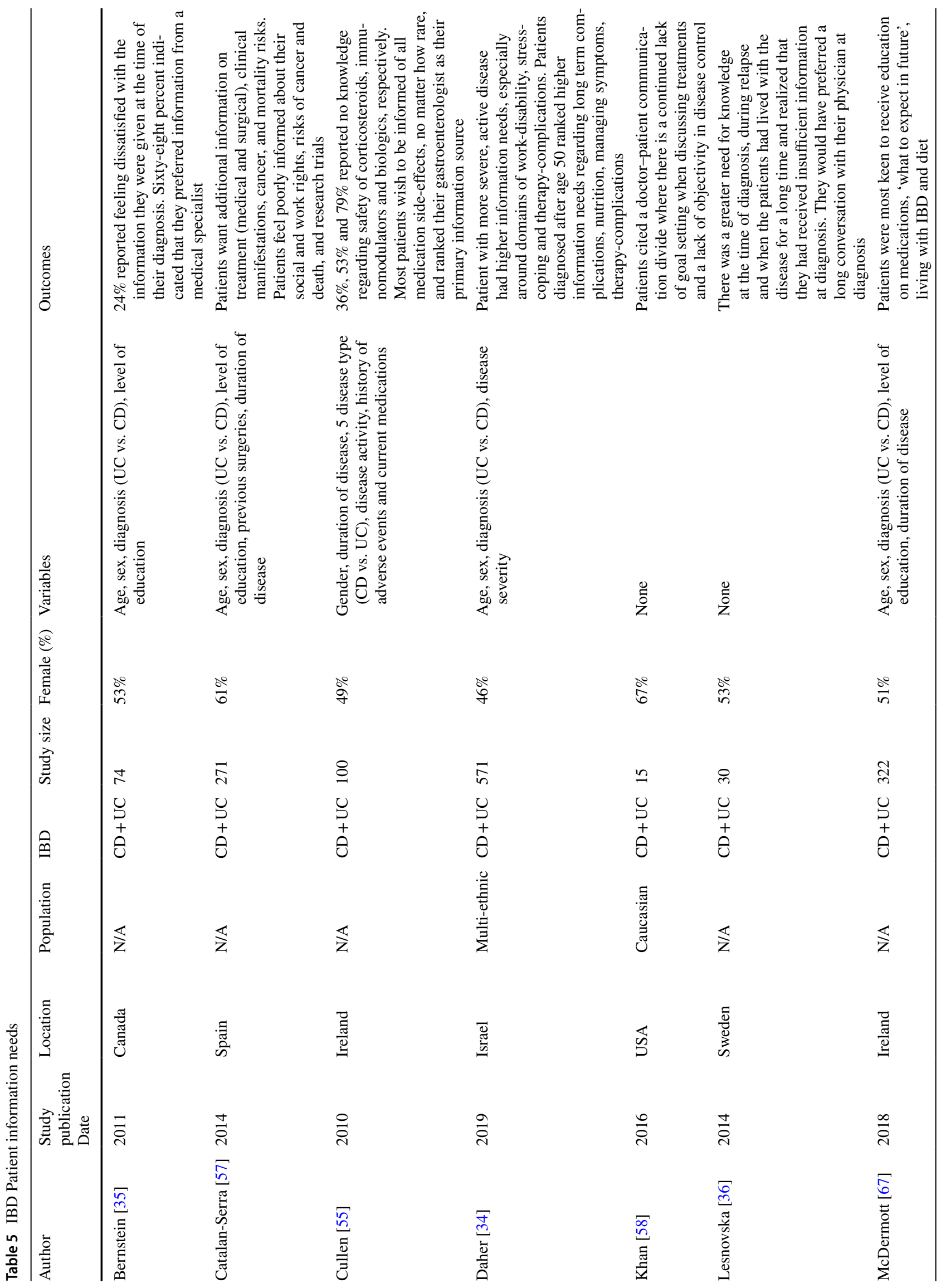




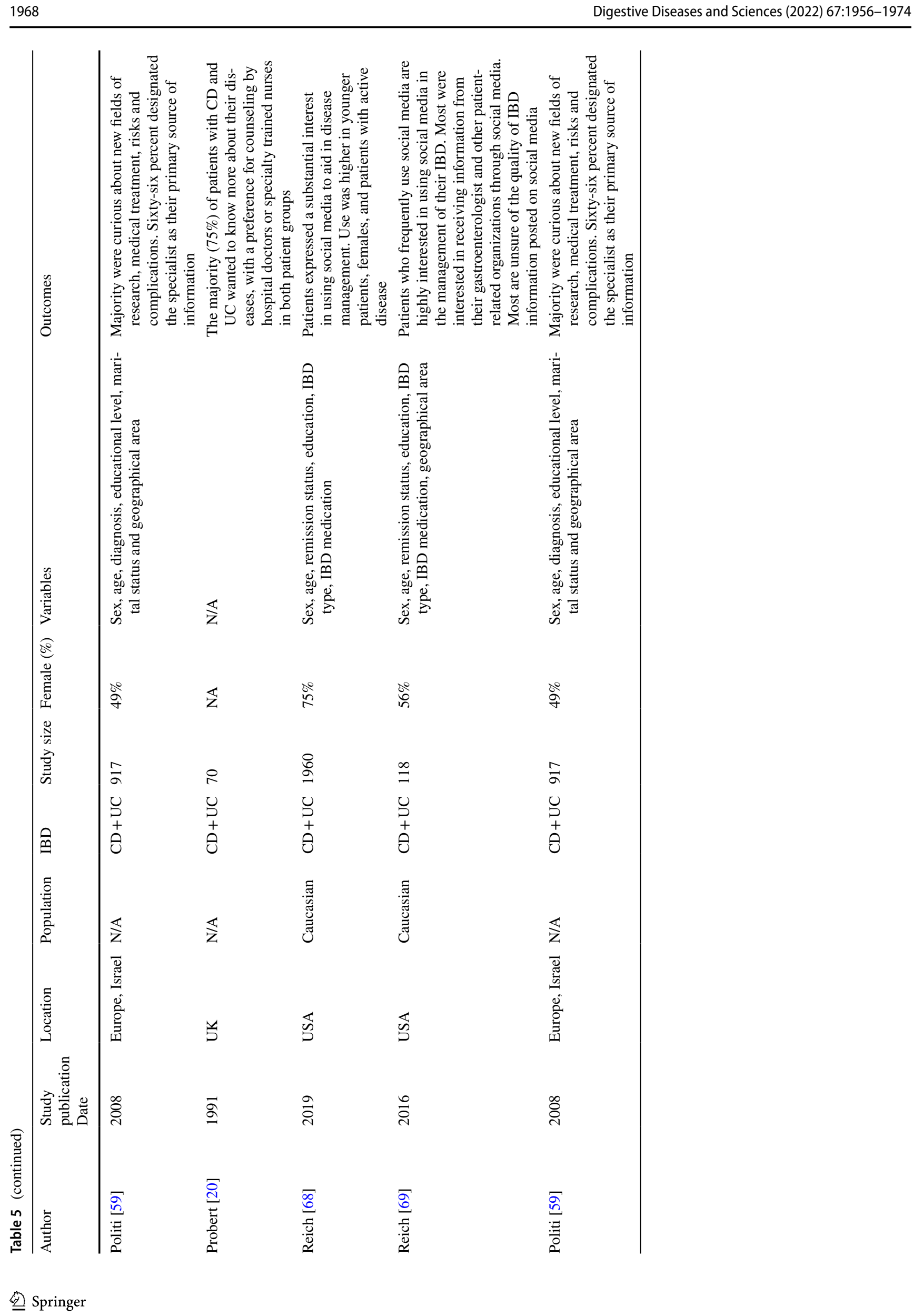




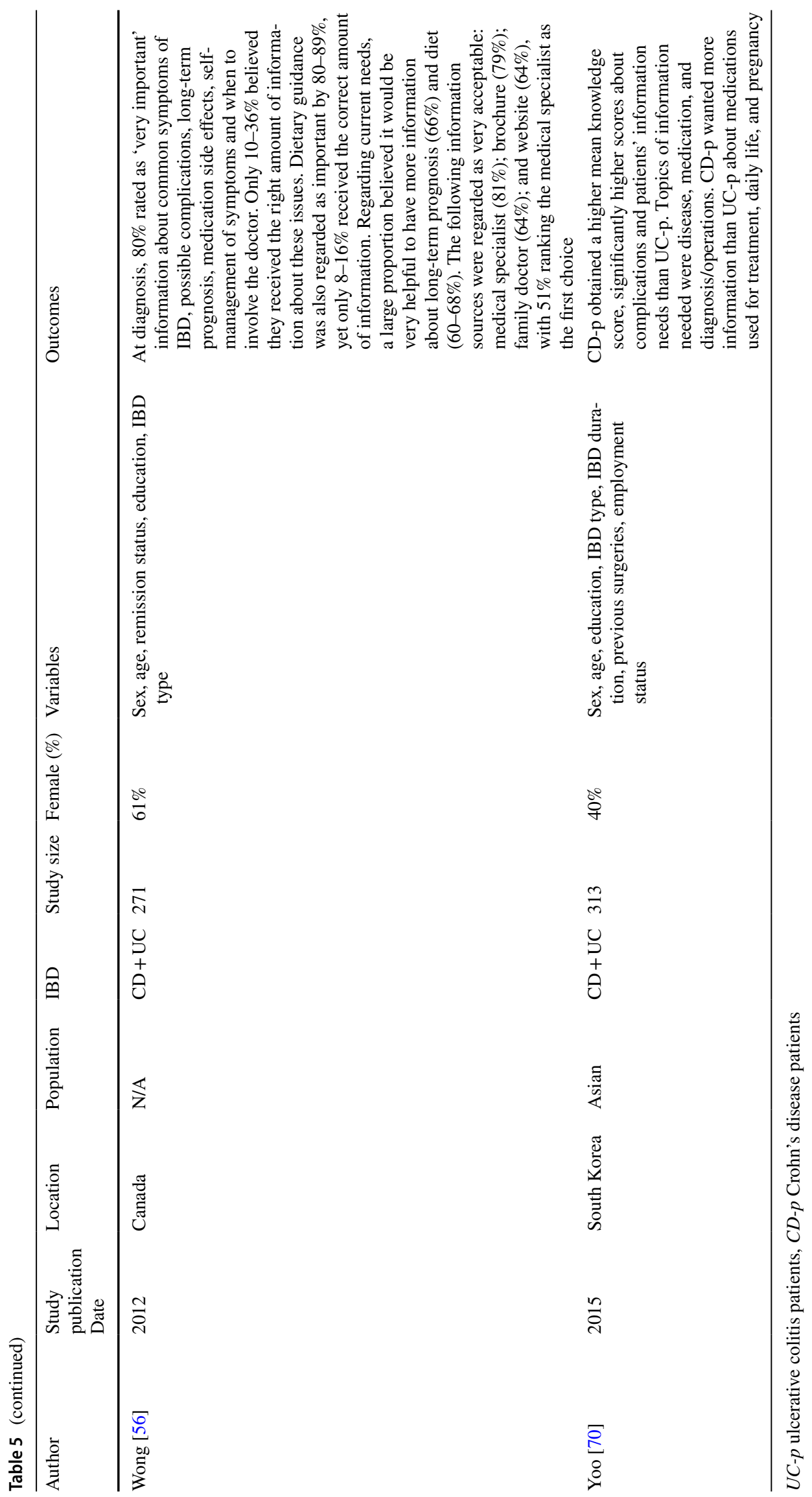




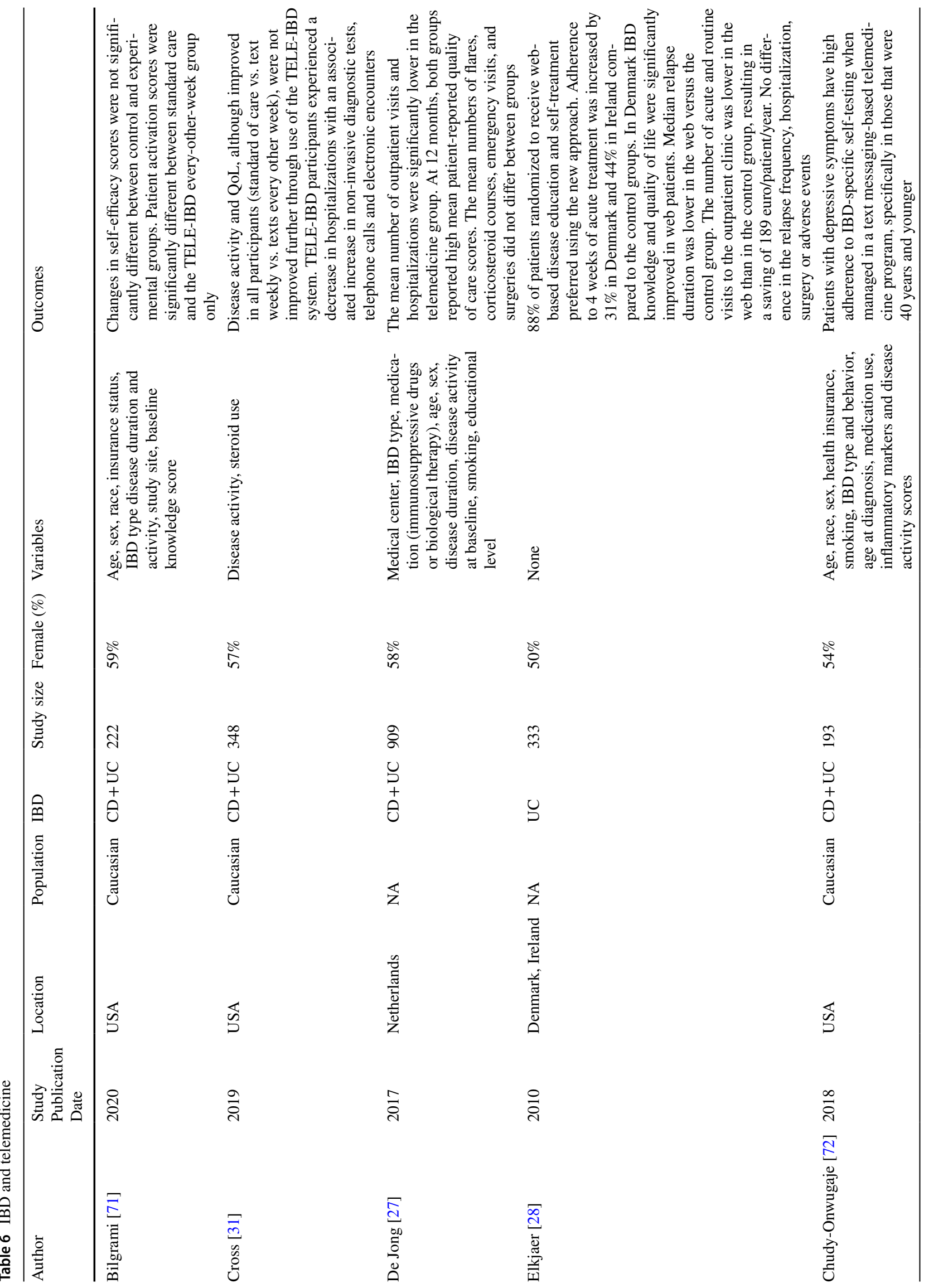




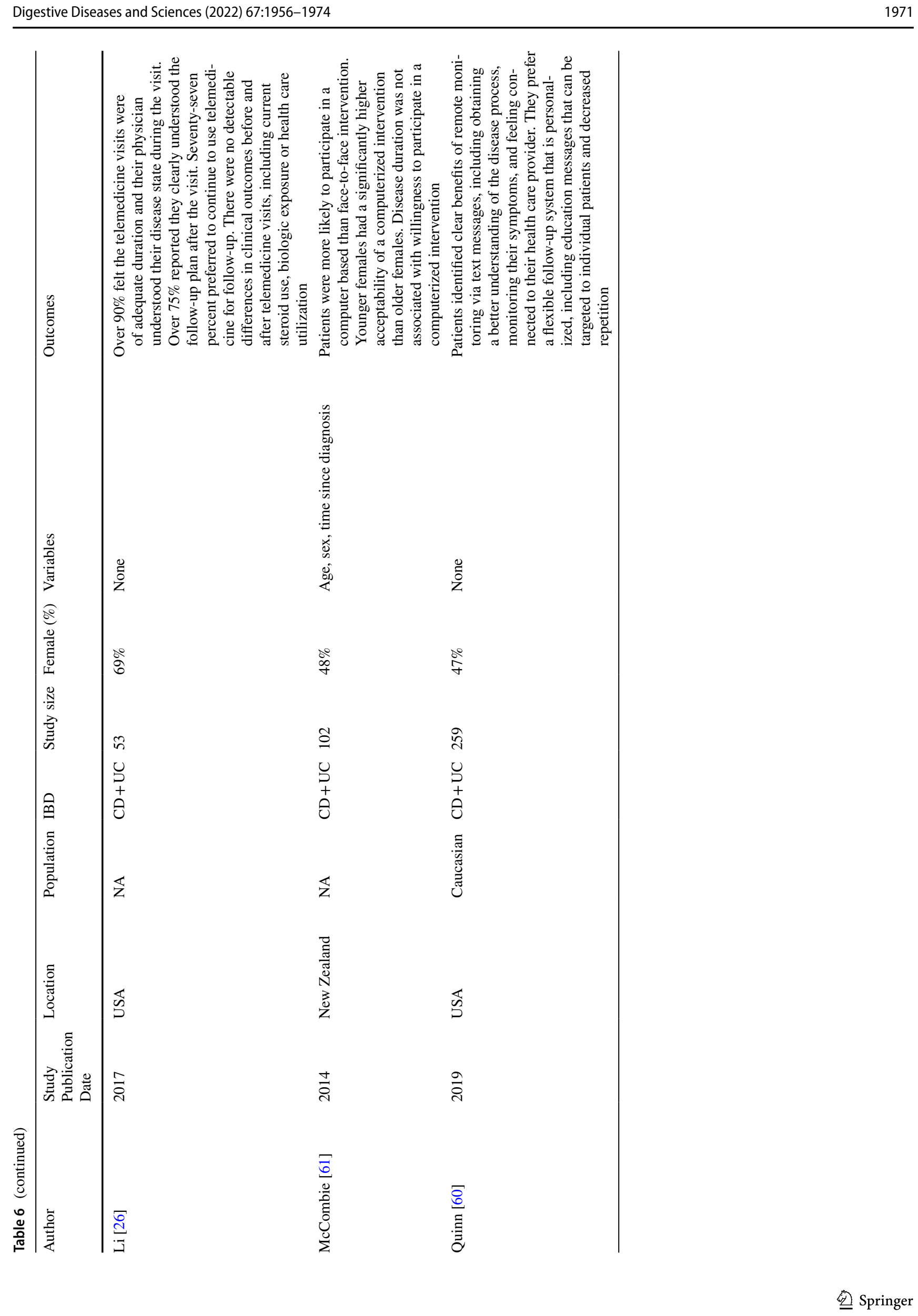


UC versus CD but UC patients valued therapeutic efficacy more, whereas $\mathrm{CD}$ patients valued side effect profile [37]. It is important to be aware of these discrepancies to help with the decision-making process during active disease.

During remission, patients viewed safety, long-term outcomes and novelties in research and development to be important. Boeri et al. demonstrated that patients considered symptom control to be 2.5 times more important than time to symptom improvement and a 5-years risk of malignancy almost as important as long-term symptom control [38]. Nevertheless, for physicians, symptom control was the most important attribute and was five times as important as the risk of malignancy [38]. Furthermore, many patients are concerned about IBD research and development of their illness during remission [52].

Regarding information needs, patients preferred to receive the primary source of information from a gastroenterologist [35, 55]. Pittet et al. [29] looked at patient expectations in IBD and demonstrated that the two most important included good coordination between general practitioners and specialists and information on treatment adverse events. Women had higher level of expectations than men. Other expectations were linked to information, communication, daily care, and disease recognition. In a large study of 728 patients, Pittet et al. [52] showed that information seeking increased in those with active disease and for $\mathrm{CD}$ with high levels of perceived stress.

Nevertheless, patients and physicians' perceptions in IBD may differ and that may hinder high quality care. For instance, physicians estimated the severity of IBD to be lower than patients' reported disease severity and felt that the disease had lower impact to lead a normal life compared to patients [66]. A study by Casellas et al. showed that only $12.8 \%$ of patients indicated having a completely normal colonoscopy as a preferred objective [25]. This is different from physician treatment goals of attaining endoscopic healing. A study by Boeri et al. showed that both patients and physicians considered long-term symptom control the most important attribute relative to others; however, patients were more concerned regarding the risk of malignancy compared to physicians [38].

Amidst this pandemic era, telemedicine has become an alternative option of managing patients with IBD when access to care may be difficult. Telemedicine has shown to be feasible and acceptable in patients with IBD and reduced the number of outpatient visits and consequently healthcare expenditure [27, 28]. IBD and telemedicine existed even before the pandemic era. A paper by Quinn et al., showed clear benefits of remote monitoring by text messages including obtaining a better understanding of the disease process, monitoring their symptoms and feeling connected to the health care provider. It also provided a flexible follow up system that is personalized [60]. Most patients are satisfied with telemedicine and this has helped them to be more involved in their own management. Patients have been able to do their self-management at home and contact the clinic once appropriate. A study by Elkjaer et al. [28] showed that $88 \%$ of web patients preferred adhering to either a web-group receiving disease-specific education and selftreatment versus usual care over a 12 months period. In web patients, IBD knowledge, adherence to treatment and QoL improved. Median relapse duration, number of acute and routine visits to the outpatient clinic was lower in the web than in the control group, resulting in a saving of healthcare expenditure [28]. This all reinforces the importance of shared decision-making and self-management. We believe patient expectations would change in the twenty-first century with more emphasis on virtual clinics, telemedicine, patient involvement in their own care including self-monitoring and shared decision-making regarding treatment.

The strength of the present study is focused on harmonized care practices with a high emphasis on delivering quality care to patients with IBD. This systematic review serves as a repertoire for what is available around this important topic and how we can build on shared decision-making in IBD to improve patient care. This systematic review further serves as a comprehensive measure of quality indicators in IBD. The limitation includes that most of the studies discovered in the systematic review are descriptive in nature; nevertheless this is expected when describing quality indicators in IBD. This review includes papers published internationally, but there is no discussion of how differences in healthcare practices across countries (payment, average time with the physician, whether multidisciplinary care is common) may impact findings.

In conclusion, this systematic review demonstrates the importance of patient expectations and perspectives in inflammatory bowel disease. Involving your patient early on with shared decision-making is important to provide optimal patient care despite the misalignment between physician and patient perspectives. Tracking and optimizing quality indicators as well optimizing access to IBD care and self-management are important for developing a model for shared decision-making in IBD. Further research is needed to align patient and physician expectations in order to improve patient care.

Supplementary Information The online version contains supplementary material available at https://doi.org/10.1007/s10620-021-07025-y.

Author's contributions $\mathrm{AA}$ and $\mathrm{BB}$ were involved in data collection and methodological quality assessment. AA, BB and P.L.L were involved in manuscript writing. T.B, W.A, P.L.L and M.A were involved in manuscript editing. P.L.L was involved in study design.

Funding None. 


\section{Declarations}

Conflict of interest The authors declare that they have no conflict of interest.

\section{References}

1. Barreiro-de Acosta M et al. P639 Influence of extraintestinal manifestations in health-related quality of life in inflammatory bowel disease patients. J Crohn's and Colitis 2013;7:S266-S267.

2. Ng SC et al. Worldwide incidence and prevalence of inflammatory bowel disease in the 21 st century: a systematic review of population-based studies. Lancet 2018;390:2769-2778.

3. Colombel JF et al. Effect of tight control management on Crohn's disease (CALM): a multicentre, randomised, controlled phase 3 trial. Lancet 2018;390:2779-2789.

4. Colombel JF et al. Early mucosal healing with infliximab is associated with improved long-term clinical outcomes in ulcerative colitis. Gastroenterology 2011;141:1194-1201.

5. Frøslie KF et al. Mucosal healing in inflammatory bowel disease: results from a Norwegian population-based cohort. Gastroenterology 2007; 133:412-422.

6. Shah SC et al. Mucosal healing is associated with improved long-term outcomes of patients with ulcerative colitis: a systematic review and meta-analysis. Clin Gastroenterol Hepatol 2016;14:1245-1255.e8.

7. Shah SC et al. Systematic review with meta-analysis: mucosal healing is associated with improved long-term outcomes in Crohn's disease. Aliment Pharmacol Ther 2016;43:317-333.

8. Turner D et al. STRIDE-II: An Update on the Selecting Therapeutic Targets in Inflammatory Bowel Disease (STRIDE) Initiative of the International Organization for the Study of IBD (IOIBD): Determining Therapeutic Goals for Treat-to-Target strategies in IBD. Gastroenterology, 2020.

9. Danese $S$ et al. Unmet medical needs in ulcerative colitis: an expert group consensus. Dig Dis 2019;37:266-283.

10. Hindryckx $P$ et al. Incidence, prevention and management of antidrug antibodies against therapeutic antibodies in inflammatory bowel disease: a practical overview. Drugs 2017;77:363-377.

11. Moss AC, Brinks V, Carpenter JF. Review article: immunogenicity of anti-TNF biologics in IBD - the role of patient, product and prescriber factors. Aliment Pharmacol Ther 2013;38:1188-1197.

12. Rutgeerts $\mathbf{P}$ et al. Efficacy of ustekinumab for inducing endoscopic healing in patients with Crohn's disease. Gastroenterology 2018;155:1045-1058.

13. D'Amico F et al. Tofacitinib in the treatment of ulcerative colitis: efficacy and safety from clinical trials to real-world experience. Therap Adv Gastroenterol, 2019. 12.

14. Fiorino $\mathrm{G}$ et al. Quality of care standards in inflammatory bowel diseases: a European Crohn's and colitis organisation [ECCO] position paper. J Crohns Colitis 2020;14:1037-1048.

15. Morishige $\mathrm{R}$ et al. Preferences regarding shared decision-making in Japanese inflammatory bowel disease patients. Adv Therapy 2017;33:2242-2256.

16. Bitton $A$ et al. Selection of quality Indicators in IBD: integrating physician and patient perspectives. Inflammatory Bowel Diseases 2019;25:403-409.

17. Hodgkins $\mathrm{P}$ et al. Patient preferences for first-line oral treatment for mild-to-moderate ulcerative colitis: a discrete-choice experiment. The patient 2012;5:33-44.

18. Gray JR, Leung E, Scales J. Treatment of ulcerative colitis from the patient's perspective: a survey of preferences and satisfaction with therapy. Aliment Pharmacol Ther 2009;29:1114-1120.
19. Hazlewood GS et al. Patient preferences for maintenance therapy in Crohn's disease: a discrete-choice experiment. PloS one 2020;15:e0227635.

20. Probert CS, Mayberry JF. Inflammatory bowel disease: patients' expectations in the 1990s. J R Soc Med 1991;84:131-132.

21. Keil $\mathrm{R}$ et al. Adherence, risk factors of non-adherence and patient's preferred treatment strategy of mesalazine in ulcerative colitis: multicentric observational study. Scand J Gastroenterol 2018;53:459-465.

22. Bewtra M, Johnson FR. Assessing patient preferences for treatment options and process of care in inflammatory bowel disease: a critical review of quantitative data. The patient 2013;6:241-255.

23. Moher D, Tetzlaff J, Altman DG. Preferred reporting items for systematic reviews and meta-analyses: the PRISMA statement. Ann Int Med 2009;151:264-269.

24. O'Brien BC, Beckman TJ, Reed DA, Cook DA. Standards for reporting qualitative research: a synthesis of recommendations. Acad Med. 2014;89:1245-1251.

25. Casellas F et al. Patient preferences for inflammatory bowel disease treatment objectives. Digest Liver Dis Off J Ital Soc Gastroenterol Ital Assoc Study Liver 2017;49:152-156.

26. Li SX et al. Delivering high value inflammatory bowel disease care through telemedicine visits. Inflamm Bowel Dis 2017;23:1678-1681.

27. de Jong MJ et al. Telemedicine for management of inflammatory bowel disease (myIBDcoach): a pragmatic, multicentre, randomised controlled trial. Lancet 2017;390:959-968.

28. Elkjaer $\mathrm{M}$ et al. E-health empowers patients with ulcerative colitis: a randomised controlled trial of the web-guided "Constant-care" approach. Gut 2010;59:1652-1661.

29. Pittet $\mathrm{V}$ et al. Patient-reported healthcare expectations in inflammatory bowel diseases. PloS one 2018;13:e0197351.

30. Hagelund LM, Elkjær Stallknecht S, Jensen HH, Quality of life and patient preferences among Danish patients with ulcerative colitis - results from a survey study. Curr Med Res Opin 2020:1-9.

31. Cross RK et al. A randomized controlled trial of telemedicine for patients with inflammatory bowel disease (TELE-IBD). Am J Gastroenterol 2019;114:472-482.

32. Arseneau $\mathrm{KO}$ et al. Do patient preferences influence decisions on treatment for patients with steroid-refractory ulcerative colitis? Clin Gastroenterol Hepatol Off Clin Pract J Am Gastroenterol Assoc 2006;4:1135-1142.

33. Casellas F et al. Patients' perceptions, attitudes, and experiences about the management of mild-to-moderate ulcerative colitis. $J$ Crohns Colitis 2014;8:1097-1107.

34. Daher $\mathrm{S}$ et al. Inflammatory bowel disease patient profiles are related to specific information needs: A nationwide survey. World J Gastroenterol 2019;25:4246-4260.

35. Bernstein KI et al. Information needs and preferences of recently diagnosed patients with inflammatory bowel disease. Inflamm Bowel Dis 2011;17:590-598.

36. Lesnovska KP et al. What do patients need to know? Living with inflammatory bowel disease. J Clin Nurs 2014;23:1718-1725.

37. Almario CV et al. Optimizing selection of biologics in inflammatory bowel disease: development of an online patient decision aid using conjoint analysis. Am J Gastroenterol 2018;113:58-71.

38. Boeri $\mathrm{M}$ et al. Patient and physician preferences for ulcerative colitis treatments in the United States. Clin Exp Gastroenterol 2019;12:263-278.

39. Bewtra M et al. Variation among patients With Crohn's disease in benefit vs risk preferences and remission time equivalents. Clin Gastroenterol Hepatol Off Clin Pract J Am Gastroenterol Assoc 2020;18:406.

40. Bewtra $M$ et al. Patient preferences for surgical versus medical therapy for ulcerative colitis. Inflamm Bowel Dis 2014;20:103-114. 
41. Casellas F, Ginard D, Riestra S. Patient satisfaction in the management of mild-to-moderate ulcerative colitis: Results of a Delphi study among patients and physicians. Digest Liver Dis Off J Ital Soc Gastroenterol Ital Assoc Study Liver 2016;48:1172-1179.

42. Gregor JC et al. Inflammatory bowel disease patients prioritize mucosal healing, symptom control, and pain when choosing therapies: results of a prospective cross-sectional willingness-to-pay study. Patient Prefer Adherence 2018;12:505-513.

43. Johnson FR et al. Crohn's disease patients' risk-benefit preferences: serious adverse event risks versus treatment efficacy. Gastroenterology 2007;133:769-779.

44. Johnson FR et al. Are gastroenterologists less tolerant of treatment risks than patients? Benefit-risk preferences in Crohn's disease management. J Manage Care Pharm JMCP 2010;16:616-628.

45. Lai $\mathrm{C}$ et al. Patient decision-making in severe inflammatory bowel disease: the need for improved communication of treatment options and preferences. Colorectal Dis Off J Assoc Coloproctol Great Brit Ireland 2019;21:1406-1414.

46. Peake STC et al. Patient preference in choosing biological therapy in Crohn's disease. Inflamm Bowel Dis 2011;17:E79.

47. Loftus EV Jr. A practical perspective on ulcerative colitis: patients' needs from aminosalicylate therapies. Inflamm Bowel Dis 2006;12:1107-1113.

48. Peyrin-Biroulet L et al. Treatment satisfaction, preferences and perception gaps between patients and physicians in the ulcerative colitis CARES study: A real world-based study. Digest Liver Dis Off J Ital Soc Gastroenterol Ital Assoc Study Liver 2016;48:601-607.

49. Lichtenstein G, Kelly J, McDonald SS, Zanutto EL, Hendricks D, Rahman MI. Assessing drug treatment preferences of patients with Crohn's disease. PatientPatient-Cent Outcomes Res 2010;3:113-123.

50. Barsky $\mathrm{M}$ et al, understanding determinants of patient preferences between stool tests and colonoscopy for the assessment of disease activity in inflammatory bowel disease. Dig Dis Sci 2020.

51. Noiseux I et al. Inflammatory bowel disease patient perceptions of diagnostic and monitoring tests and procedures. BMC Gastroenterology 2019;19(1):N.PAG-N.PAG.

52. Pittet $\mathrm{V}$ et al. Information needs and concerns of patients with inflammatory bowel disease: what can we learn from participants in a Bilingual Clinical Cohort? PloS one 2016;11:e0150620.

53. Vasudevan A, Arachchi A, van Langenberg DR. Assessing patient satisfaction in inflammatory bowel disease using the QUOTEIBD survey: a small step for clinicians, a potentially large step for improving quality of care. J Crohn's Colitis 2013;7:e367-e374.

54. Vaucher $\mathrm{C}$ et al. Patients and gastroenterologists' perceptions of treatments for inflammatory bowel diseases: do their perspectives match? Scand J Gastroenterol 2016;51:1056-1061.

55. Cullen $\mathrm{G}$ et al. Perceptions of medication safety among patients with inflammatory bowel disease. Scand J Gastroenterol 2010;45:1076-1083.

56. Wong $\mathrm{S}$ et al. The information needs and preferences of persons with longstanding inflammatory bowel disease. Can J Gastroenterol 2012;26:525-531.

57. Catalán-Serra I et al. Information resources used by patients with inflammatory bowel disease: satisfaction, expectations and information gaps. Gastroenterol Hepatol 2015;38:355-363.
58. Khan $\mathrm{S}$ et al., Unmet communication and information needs for patients with IBD: implications for mobile health technology. Brit J Med Med Res, 2016;12(3).

59. Politi $\mathrm{P}$ et al. Communication of information to patients with inflammatory bowel disease: A European Collaborative Study in a multinational prospective inception cohort. J Crohn's and Colitis 2008;2:226-232.

60. Quinn CC et al. The telemedicine for patients with inflammatory bowel disease (TELE-IBD) clinical trial: qualitative assessment of participants' perceptions. J Med Int Res 2019;21:e14165.

61. McCombie A, Gearry R, Mulder R. Preferences of inflammatory bowel disease patients for computerised versus face-to-face psychological interventions. J Crohn's and Colitis 2014;8:536-542.

62. Baars JE et al. Patients' preferences regarding shared decisionmaking in the treatment of inflammatory bowel disease: results from a patient-empowerment study. Digestion 2010;81:113-119.

63. Gonczi L et al. Quality of care indicators in inflammatory bowel disease in a tertiary referral center with open access and objective assessment policies. Digest Liver Dis Off J Ital Soc Gastroenterol Ital Assoc Study Liver 2018;50:37-41.

64. Nene $\mathrm{S}$ et al. Benefits of implementing a rapid access clinic in a high-volume inflammatory bowel disease center: Access, resource utilization and outcomes. World J Gastroenterol 2020;26:759-769.

65. Vavricka SR et al. Systematic assessment of factors influencing preferences of Crohn's disease patients in selecting an anti-tumor necrosis factor agent (CHOOSE TNF TRIAL). Inflamm Bowel Dis 2012;18:1523-1530.

66. Rubin DT et al. Impact of ulcerative colitis from patients' and physicians' perspectives: results from the UC: NORMAL survey. Inflamm Bowel Dis 2009;15:581-588.

67. McDermott E et al. Patient education in inflammatory bowel disease: a patient-centred, mixed methodology Study. J Crohns Colitis 2018;12:419-424.

68. Reich $\mathrm{J}$ et al. Social media use and preferences in patients with inflammatory bowel disease. Inflamm Bowel Dis 2019;25:587-591.

69. Reich $\mathrm{J}$ et al. A survey of social media use and preferences in patients with inflammatory bowel disease. Inflamm Bowel Dis 2016;22:2678-2687.

70. Yoo YS, Cho OH, Cha KS. Disease-related knowledge and information needs among inflammatory bowel disease patients in Korea. Gastroenterol Nurs 2015;38:455-463.

71. Bilgrami $\mathrm{Z}$ et al. Effect of telemedicine for inflammatory bowel disease on patient activation and self-efficacy. Digest Dis Sci 2020;65:96-103.

72. Chudy-Onwugaje $\mathrm{K}$ et al. Age modifies the association between depressive symptoms and adherence to self-testing with telemedicine in patients with inflammatory bowel disease. Inflamm Bowel Dis 2018;24:2648-2654.

Publisher's Note Springer Nature remains neutral with regard to jurisdictional claims in published maps and institutional affiliations. 